\title{
Macroscopic Extramedullary Hematopoiesis Resembling Hepatic Metastases in Prostate Cancer
}

Romero-Laorden $\mathbf{N}^{1 *}$, Jara $\mathrm{C}^{2}$, Pinedo $\mathrm{F}^{2}$, de la Cruz $\mathbf{R}^{2}$, Hernando $\mathrm{S}^{2}$, Cámara $\mathrm{JC}^{2}$, Hurtado $\mathrm{A}^{2}$, Olier $\mathrm{C}^{2}$, Mielgo $\mathrm{X}^{2}$ and Garcia-Donas $\mathrm{J}^{1}$

${ }^{1}$ Clara Campal Comprehensive Cancer Center, Hospital Universitario HM Sanchinarro, Spain

${ }^{2}$ Hospital Universitario Fundación Alcorcón, Spain

*Corresponding author: Nuria Romero-Laorden, c/Budapest 128922 Alcorcón, Madrid, Spain, Tel: +34916219490; E-mail: nuriaromerolaorden@gmail.com

Received date: Jul 23, 2015; Accepted date: Aug 25, 2015; Published date: Aug 27, 2015

Copyright: (c) 2015 Romero-Laorden N, et al. This is an open-access article distributed under the terms of the Creative Commons Attribution License, which permits unrestricted use, distribution, and reproduction in any medium, provided the original author and source are credited.

\begin{abstract}
Extramedullary hematopoiesis is a rare entity to consider in patients with cancer and signs of bone marrow infiltration that can involve a diagnosis challenge in clinical practice. We report the case of a metastatic prostate cancer patient progressing with liver nodes and hepatic dysfunction symptoms that presented a great response to an alternative chemotherapy schedule regimen used to avoid liver toxicity of taxanes.
\end{abstract}

Keywords: Prostate cancer; Hematopoiesis extramedullar; Hepatic disease

\section{Case}

A 59-year-old male previously diagnosed of stage IV (bone metastasis), Gleason $7(4+3)$ prostate adenocarcinoma was admitted to the emergency room of our institution because of sudden severe jaundice on September 2007. On physical examination hepatomegaly was found, and blood test showed total bilirubin $26 \mathrm{mg} / \mathrm{dl}$, direct bilirubin 20 mg/dl, LDH 543 U/L, ALT 33.00 U/L, AST 61 U/L, ALP 595 U/L, GGT 657 U/L. CT-scan revealed multiple hypodense liver masses (Figure 1), scintigraphy showed super-scan bone pattern.

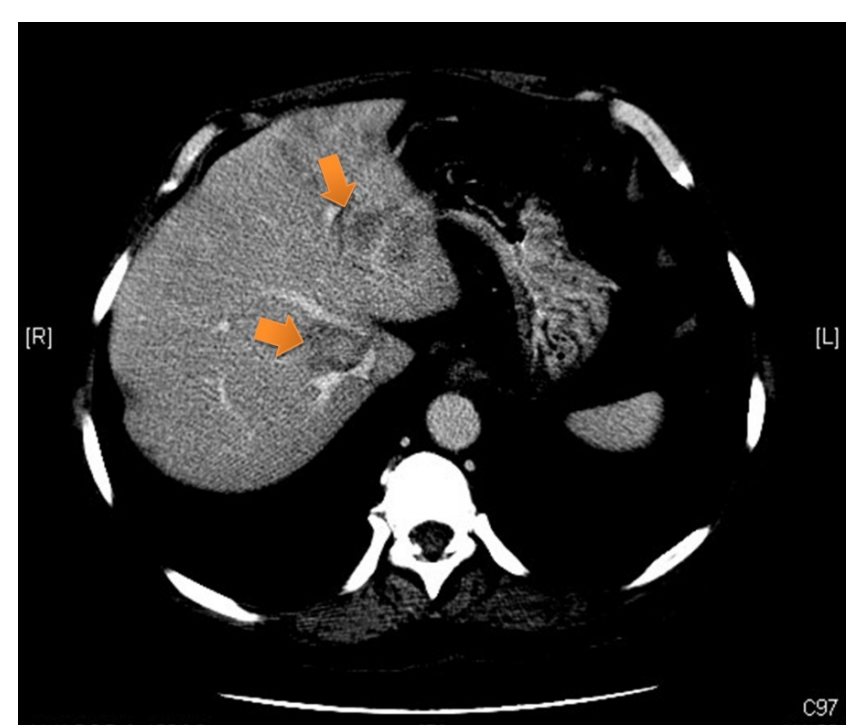

Figure 1: scintigraphy showing super-scan bone pattern.
The patient had been on complete androgen blockade with gosereline acetate $10.8 \mathrm{mg}$ depot quarterly plus oral bicalutamide 50 mg daily, for 1 year. Though initially PSA had decreased, biochemical progression was observed two months before admission, getting PSA $2160 \mathrm{ng} / \mathrm{ml}$.

Hepatic lesions were judged as metastasis, and chemotherapy was considered for treatment in the setting of castration resistant prostate cancer (CRPC). As high bilirrubin level precluded the use of any taxane, a combination of drugs with exclusive renal elimination, cisplatin and iphosphamide, was administered. Grade 2 neutropenia was observed after $2^{\text {nd }}$ cycle, so prophylactic granulocyte-colony stimulating factors were associated for 5 days in all subsequent cycles. The patient experienced quick improvement with PSA decreasing to $470 \mathrm{ng} / \mathrm{ml}$ and bilirubin coming into normal range after third cycle. Hepatic masses disappeared after the 5th cycle.

The patient did well until January 2008 when PSA rose to $644 \mathrm{ng} / \mathrm{ml}$ without hepatic abnormalities. Docetaxel plus prednisone were administered for ten cycles with partial response and no relevant toxicities.

In December 2008 the patient developed progressive jaundice reaching total bilirubin of $24 \mathrm{mg} / \mathrm{dl}$ and direct bilirubin of $19 \mathrm{mg} / \mathrm{dl}$. LDH was 682 U/L, ALT 86 U/L, AST 71 U/L, ALP 506 U/L, GGT 1099 $\mathrm{U} / \mathrm{L}$, and PSA rose again to $1151 \mathrm{ng} / \mathrm{ml}$. Despite metronomic ciclofosphamide plus prednisone were started, general condition worsened fast so he was admitted in the oncology ward. CT-scan demonstrated multiple liver lesions, almost identical to those seen the year before, and no biliary obstruction. Core-Biopsy of one of the lesions showed liver parenchyma architecture conserved, associated to centrolobulillar cholestasis and ductal regeneration signs that suggested toxic origin. Sinusoid megakaryocytes and hematopoietic areas were observed, with final diagnosis of extramedullary hematopoiesis. No neoplastic invasion was found (Figure 2). 


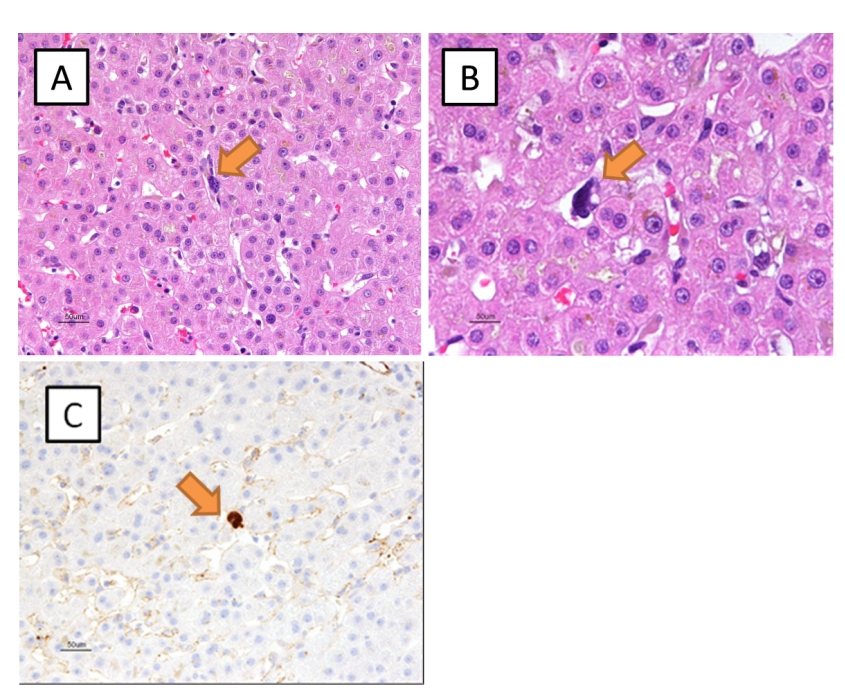

Figure 2: Core-Biopsy of one of the lesions showed liver parenchyma architecture conserved, associated to centrolobulillar cholestasis and ductal regeneration signs that suggested toxic origin.

Monotherapy with Cisplatin was reintroduced without response, so the patient died two weeks later from disease progression.

\section{Discussion}

Extramedullary hematopoiesis (EMH) is defined as the production of blood elements outside the bone marrow and it is a physiological process during prenatal life, occurring then in the yolk sac and reticuloendothelial system. In adult humans it is considered as a compensatory mechanism for abnormal hematopoiesis when red marrow is unable to work. The incidence is less than $10 \%$ of cancer patients with metastatic disease [1]. Solid tumors most commonly involved are lung, breast and prostate, with a late onset in advanced stages when the function of the bone marrow is severely disturbed [2].

$\mathrm{EMH}$ is a poorly understood phenomenon, most frequently seen in hematological disorders where bone marrow massive infiltration leads to stem cells migration. Any organ can be involved, though the spleen followed by the liver, are typically the most frequent sites [3].

It is usually an asymptomatic process described as a microscopic finding. However, mass-forming presentation has been documented previously mimicking clinically and radiologically a neoplasm [4-6]. Thus, this entity should be considered in the differential diagnosis of patients with bone marrow disorders.

To the best of our knowledge this is the first time that the implications of EMH in solid tumors management and treatment selection are discussed.

First, it is important to emphasize that conditions most frequently leading to $\mathrm{EMH}$ (the presence of hematologic disorders or prior exposure to chemotherapy) were not present in our patient [7]. Additionally, there was a clear correlation between tumor and EMH outcomes, with both entities evolving in parallel. Thus, advanced prostate cancer can reliably be considered as the primary cause of $\mathrm{EMH}$ in this case.
Since radiological findings are not specific, EMH should be kept in mind along the differential diagnosis of liver masses. Evolution after chemotherapy could even confuse radiological evaluation, simulating responses due to an improvement in bone marrow affection as in our case. Fine-needle aspiration biopsy has demonstrated to be a reliable method of diagnosing foci of hematopoiesis, though megakaryocytes can mimic malignant neoplastic cells, particularly if EMH is not considered in the diagnosis [4]. So, pathological confirmation can be critical to take therapeutic decisions, mainly in diseases where discard liver metastasis can lead to consider a curative strategy.

From our prospective, the most interesting aspect of this case is how EMH conditioned the therapeutic approach of the underlying prostate cancer and the clinical behavior of the liver lesions along the disease. Interestingly, liver infiltration by hematopoietic cells had led to a severe jaundice that precluded the use of taxanes (the only chemotherapeutic agents that have demonstrated to improve survival in CRPC) [8-10].

As these compounds are excreted through the bile, the risk of severe toxicity was considered unacceptable. For that reason an alternative regimen was prescribed, based on activity published with the combination of cisplatin plus ifosfamide in a small serie of 18 CRPC cases that revealed responses in $50 \%$ of patients treated. These drugs are eliminated through the urine so toxicity was low, with grade 2 neutropenia as the only remarkable adverse event. The quick improvement of bilirubin levels following a PSA decrease, show how the outcome of EMH relies on the evolution of the causing condition.

Moreover, normalization of bilirubin levels finally allowed the patient to receive docetaxel, which was also well tolerated, achieving a prolonged partial response.

Since this case was treated before the irruption of the new hormonotherapies for CRPC we can only speculate with the impact of maintaining the initial response with abiraterone or enzalutamide $[11,12]$. Otherwise, the favorable response observed after cisplatin, a DNA-damaging agent could point out a patient harboring DNA repair pathway aberrations (present in $23 \%$ of metastatic CRPC as revealed by recent publications) and a possible candidate to receive new strategies as PARP inhibitors [13].

In conclusion, EMH is a rare entity that needs to be suspected in patients with cancer and bone infiltration. Since radiological findings are not specific, histopathological confirmation is mandatory. An adequate therapeutic selection of the underlying condition, considering the clinical implications of $\mathrm{EMH}$, can highly impact the outcome of the disease.

\section{References}

1. http://emedicine.medscape.com/article/204647-overview

2. Makoni SN, Laber DA (2004) Clinical spectrum of myelophthisis in cancer patients. Am J Hematol 76: 92-93.

3. O'Keane JC, Wolf BC, Neiman RS (1989) The pathogenesis of splenic extramedullary hematopoiesis in metastatic carcinoma. Cancer 63: 1539-1543.

4. Policarpio-Nicolas ML, Bregman SG, Ihsan M, Atkins KA (2006) Massforming extramedullary hematopoiesis diagnosed by fine-needle aspiration cytology. Diagn Cytopathol 34: 807-811.

5. Tamiolakis D, Venizelos J, Prassopoulos P, Simopoulos S, Bolioti S, et al. (2004) Intrahepatic Extramedullary Hematopoietic Tumor Mimicking Metastatic Carcinoma from a Colonic Primary. Onkologie 27: 65-67. 
Citation: Romero-Laorden N, Jara C, Pinedo F, de la Cruz R, Hernando S, et al. (2015) Macroscopic Extramedullary Hematopoiesis Resembling Hepatic Metastases in Prostate Cancer. J Cytol Histol 6: 356. doi:10.4172/2157-7099.1000356

Page 3 of 3

6. Lemos LB, Baliga M, Benghuzzi HA, Cason Z (1997) Nodular hematopoiesis of the liver diagnosed by fine-needle aspiration cytology. Diagn Cytopathol 16: 51-54.

7. Wang J, Darvishian F (2006) Extramedullary hematopoiesis in breast after neoadjuvant chemotherapy for breast carcinoma. Ann Clin Lab Sci 36: 475-478.

8. Petrylak DP, Tangen CM, Hussain MH, Lara PN Jr, Jones JA, et al. (2004) Docetaxel and estramustine compared with mitoxantrone and prednisone for advanced refractory prostate cancer. N Engl J Med 351: 1513-1520.

9. Tannock IF, de Wit R, Berry WR, Horti J, Pluzanska A, et al. (2004) Docetaxel plus prednisone or mitoxantrone plus prednisone for advanced prostate cancer. N Engl J Med 351: 1502-1512.
10. de Bono JS, Oudard S, Ozguroglu M, Hansen S, Machiels JP, et al. (2010) Prednisone plus cabazitaxel or mitoxantrone for metastatic castrationresistant prostate cancer progressing after docetaxel treatment: a randomised open-label trial. Lancet 376: 1147-1154.

11. de Bono JS, Logothetis CJ, Molina A, Fizazi K, North S, et al. (2011) Abiraterone and increased survival in metastatic prostate cancer. $\mathrm{N}$ Engl J Med 364: 1995-2005.

12. Scher HI, Fizazi K, Saad F, Taplin ME, Sternberg CN, et al. (2012) Increased survival with enzalutamide in prostate cancer after chemotherapy. N Engl J Med 367: 1187-1197.

13. Robinson D, Van Allen EM, Wu YM, Schultz N, Lonigro RJ, et al. (2015) Integrative clinical genomics of advanced prostate cancer. Cell 161: 1215-1228. 